\title{
Planning a Master's Level Curriculum According to Career Space Recommendations Using Concept Mapping Techniques
}

\author{
SERGIO L. TORAL MARÍN \\ Electronic Engineering Department, University of Seville, Spain \\ ROCÍO MARTÍNEZTORRES \\ Business Administration and Marketing Department, University of Seville, Spain
}

FEDERICO J. BARRERO GARCÍA

Electronic Engineering Department, University of Seville, Spain

SERGIO GALLARDO VÁZQUEZ

Electronic Engineering Department, University of Seville, Spain

ENRIQUE VARGAS, VICENTE GONZÁLEZ AYALA

Laboratorio de Electrónica Digital, Universidad Catolica 'Nuestra Señora de la Asunción', Asunción, Paraguay

\begin{abstract}
Nowadays the European Universities are worried about how to adapt higher education to the new European Higher Education Area, as proposed in the Bologna Magna Charta Universitatum of 1998, and signed by 32 European Education Ministers. One of the key points in this higher education reform was the introduction of new Master's level curricula. These Masters will look for the professional specialization and they will have to be adapted to the specific skills demanded by the society. This paper presents the results from a cooperation project - funded by the AECI (International Cooperation Spanish Agency) and developed between the University of Seville (Spain) and the Catholic University of Asuncion (Paraguay) - by about the planning of a new master's level curriculum in digital signal processing (DSP) area, taking into account the Bologna principles and the conclusions obtained by the Career Space Consortium. A scientific method from social science, known as concept mapping techniques, was used to perform this planning. Basically, the idea of concept mapping consists of compiling the opinion from actors belonging to different environments (lecturers, researchers, workers, businessmen, etc.) related to DSP applications. The compiled data were statistically computed to cluster the opinions of the different agents. The result will be a master's level curricula adapted to the environment requirements and the social settings.
\end{abstract}

Keywords: career Space, concept mapping, DSP applications, master's level curricula, skills profiles 


\section{INTRODUCTION}

The Sorbonne declaration (Joint declaration on harmonisation of the European Higher Education Area 1998) emphasizes the creation of the European Area of Higher Education as a key way to promote citizens' mobility and employability and the Continent's overall development. European higher education institutions have accepted the challenge, and they have taken up a main role in constructing this European Area of Higher Education, based on the fundamental principles established in the Bologna Magna Charta Universitatum (Joint declaration of the European Ministers of Education 1999). Actually one of the main objectives they are engaged in is defining policies to reach a common educational system focusing on two levels, undergraduate and graduate. Access to the second cycle will require successful completion of first cycle studies, lasting a minimum of three years. The degree awarded after the first cycle level shall also be relevant to the European labour market as an appropriate level of qualification. The second cycle should lead to the master and/or doctorate degree. Its design should be embedded in the environment where it is going to be developed attending to the professional skills demanded by the society. That is, its contents should be adapted to a diversity of individual, academic and labour market needs (Communiqué of the Conference of Ministers responsible for Higher Education 2003).

This paper presents an empirical exploratory research about a master's level curricula design. A scientific tool has been used to identify the topics to be taken into account for a master's level curriculum design in the Information and Communications Technology (ICT) area. CareerSpace conclusions have been used as a starting point. Career-Space is a consortium of nine major European ICT companies. It states that substantial changes to curricula in Higher Education, especially in Engineering and Computing, are necessary to prepare new graduates for the challenges they will encounter working in ICT. The goal of the applied technique, based on concept mapping, is to adapt Career-Space conclusions and the principles of the Bologna declaration to the situation and conditions of a country outside the European Space.

The structure of the paper begins with a brief description of CareerSpace conclusions. After that, the scientific method used in the master program design is explained. The main results are shown in the following section. Finally, the conclusions drawn from the study are outlined. Even though the methodology has been used in the design of a master's level curriculum in ICT area, it can be extended to any other area.

\section{STARTING POINT: CAREER-SPACE CONCLUSIONS}

Career Space (Career-Space Project 2001a) is a consortium of nine major European ICT companies (BT, Cisco Systems, IBM Europe, Intel, 
Microsoft Europe, Nokia, Philips Semiconductors, Siemens AG, Thales). With the support of the European Commission and European Information, Communications and Consumer Electronics Industry Technology Association (EICTA), and coordinated by International Cooperation Europe Ltd., Career Space has recently set up a project to put in place a clear framework for students, education institutions and governments that describes the roles, skills and competencies required by the ICT industry in Europe.

According to Career Space, people who are creative in the use of the growing number of novel technologies and tools are needed. For this reason, engineering and computer curricula need for significant changes if new graduates are to be well prepared for the challenges they will encounter working in ICT area. It is not the intention of the Career Space Consortium to establish how to design the curricula, but to give recommendations for the content areas of new ICT curricula covering the wide variety of the required skills. The widening skills gap has been recognized, especially in information technology where increasing numbers of jobs remain unfilled. ICT graduates need reliable technical skills, both in engineering and computer industry, with especial attention to a wide systemic view. Nowadays, they do not only require good technical and creative skills across converging technologies, but also the commercial and interpersonal abilities (such as problem solving skills, life-learning conscience, etc.).

Career Space provides some guidelines as a basis for universities and other educational institutions to review and revise relevant courses. Eighteen different job profiles have been developed by Career Space Consortium (Career-Space Project 2001b). Thirteen out of these eighteen refer to ICT profiles strictly speaking, while the other five refer to crosssector (ICT and Management). The developed job profiles are shown in Table I.

Not only engineering and informatics are important disciplines in ICT curricula, but also economics, business, creative design, social sciences

TABLE I

ICT job profiles

\begin{tabular}{|c|c|}
\hline Radio Frequency (RF) Engineering & Technical Support \\
\hline Digital Design & Product Design \\
\hline Data Communications Engineering & $\begin{array}{l}\text { Integration \& Test/Implementation } \\
\& \text { Test Engineering }\end{array}$ \\
\hline $\begin{array}{l}\text { Digital Signal Processing } \\
\text { Applications Design }\end{array}$ & Systems Specialist \\
\hline Communications Network Design & ICT Marketing Management \\
\hline Software \& Applications Development & ICT Project Management \\
\hline Software Architecture and Design & Research and Technology Development \\
\hline Multimedia Design & ICT Management \\
\hline IT Business Consultancy & ICT Sales Management \\
\hline
\end{tabular}


and psychology. In some degrees these aspects are even more important than technical skills (for more details, see generic job profiles in http:// www.career-space.com).

The job profile 'Digital Signal Processing Applications Design' was used as starting point for this study, as it was the best suited to the master's level curriculum to be designed. However, the research could result on a final curricula overlapped with other job profiles. It is not the aim of this study to impose the conclusions of Career Space, but to adapt their results to a particular circumstance: the Paraguayan higher educational requirements and system. The objective of concept mapping techniques used in this work is to adapt the starting point profile to the environment requirements, so the starting point could be modified in some way.

According to Career-Space Project, Digital Signal Processing Applications Design is involved in requirement studies, simulations and performance analysis and participates in the design and optimisation of algorithms for signal modulation, detection and channel coding/decoding and implementation with signal processors and testing, SW integration and maintenance' (Career-Space Project 2001a: 19). Technical and legal knowledge have to be included. The technical complexity of the field demands a great deal of team work, usually on an international and multi-site level within the company and together with customers or even competitors. The DSP Applications Designer is also involved in an active exchange of well-prepared information via modern communication tools like e-mail, telephone and video conferencing. Team meetings are held regularly which involve national and international travel. Due to the importance of algorithms and their strong contribution to the overall system performance, highly innovative work is done constantly. The main technologies include Digital Signal Processing, Embedded Systems, Real-Time Applications, Wireless Communication Technology and System Simulation Technology. Other technical and behavioural skills are described in (Career-Space Project 2001a).

\section{METHODOLOGY TO DEFINE THE MASTER'S LEVEL CURRICULA}

A concept map is a method of structured conceptualization that can be used to develop the conceptual framework to guide an evaluation, an exercise, a plan, etc. (Martínez-Torres, Barrero, Toral, \& Gallardo 2005; Thomson 1997; Trochim 1996, 1989; Vega-Riveros et al. 1998). To develop the concept map, a procedure that uses quantitative and qualitative features is applied. At the beginning, the participants generate information through brainstorming. As part of the process, the data is structured, quantified, and analyzed using statistical methods that include a multidimensional scale and clusters analysis. Concept mapping shows the main categories of ideas (statistically identified) derived from 
the participants' input. Each subset of ideas is represented in clusters on the map. Clusters that are closest together are said to be more directly linked. The maps represent the opinion of the participants.

Following, the procedure to develop the concept map is outlined (Kolb \& Shepherd 1997):

- Selecting and preparing the participants.

- Brainstorming session.

- Structuring and rating items from 2.

- Representing the items on a concept map (using a multidimensional scale and clusters analysis).

- Interpreting the maps.

Next, a more detailed description of the above mentioned procedure applied in the Catholic University in Asunción is presented.

\section{Selection and preparation of the participants}

Choosing the right participants is one of the most important tasks to develop a concept map. Experiments show that the conceptualization is better when the process involves a wide range of experts. A broad, heterogeneous participation helps to ensure that the different points of view will be considered (Delbecq, Van de Ven, \& Gustafson 1975), thus encouraging 'constructing' the right conceptual framework.

Taking into account what explained above, 16 people participated in the different sessions. All of them were related to electronic sector in some way (lecturers, professors, doctoral students, graduates, employers, employees and researchers). The level of participation can be considered adequate and acceptable as, in order to employ the technique, Delbecq et al. recommend between 10 and 20 participants (Delbecq et al. 1975). The reasons for this selection were twofold:

1. The participation of people with a good knowledge about the natural resources and requirements in the country was considered essential. This is the only way of adapting master's level curricula to the social reality. Of course, a master's level curriculum could have been 'borrowed' from another university, but, in that case, the curriculum would not fit the demands of the Paraguayan society.

2. The participation of people with different points of view when designing a master's level curriculum is very important (McCormick 2001). The academic perception may be very different to the entrepreneurial point of view. Looking the problem from different points of view enriches the development process.

\section{Brainstorming session}

The next stage consists in establishing a list of items related to the proposed master. The brainstorming statement focus was: Identification 
of the knowledge, skills, and competences which should be part of the curricula of a master's level curriculum in Digital Signal Processing. In the brainstorming session, 77 items were identified (see Table II). All of them were considered important to be taught.

\section{Structuring and rating the items}

When a set of items that describes the conceptual domain of the given topic is established, information must be provided about how they are interrelated and establish their relative importance in relation to the master. Both tasks make up the stage of items structuring throughout the concept-mapping development process.

The first task of the working group classifies the 77 items in several groups based on their affinity with respect to some related concept. Each of the participants applies his or her personal experience to define the number of groups and items that make up each group. A similarity matrix $S$ of $n \times n$ dimension, with $n=77$, is obtained as follows: the value of each $(i, j)$ element is equal to 1 if the $i$ th and $j$ th items are grouped together, and is equal to 0 otherwise. Each item could only be placed in one group. Participants were encouraged to be imaginative, that is to say, all the items could not be placed in only one group, nor was it possible to group each item individually (obtaining the same number of groups than items to be classified). The total similarity matrix $T$ of $n \times n$ dimension is obtained as the addition of all the similarity matrices.

The second task involved rating each item according to its contribution to the goals of the master, according to the Career-Space conclusions. Then the items had to be scored using a Likert scale with values between 1 and 7, considering that 1 corresponds to 'little contribution', 7 to 'bigger contribution', and the numbers in between refers to intermediate contributions. A 'zero-contribution' value was not possible, since the brainstorming session specifically asked for those items that contributed to obtaining the master goals. Therefore all the items have some contribution.

\section{Representing the items in a concept-map form}

Subsequently, a multidimensional scale and a cluster analysis were performed on the data using MATLAB ${ }^{\text {TM }}$.

Multidimensional scaling is a mathematical tool that uses proximities between objects, subjects, or stimuli to produce a spatial representation of items. The proximities are defined as any set of numbers that expresses the amount of similarity or dissimilarity between pairs of objects, subjects, or stimuli. The objective of multidimensional scale is to find the coordinates of points in $p$-dimensional space, so that there is a solid relationship between the observed proximities and the inter-point distances (Fahrmeir \& Hamerle 1984). In concept mapping, this multidimensional scale sets up a point map that represents the set of 
TABLE II

List of brainstorming identified items

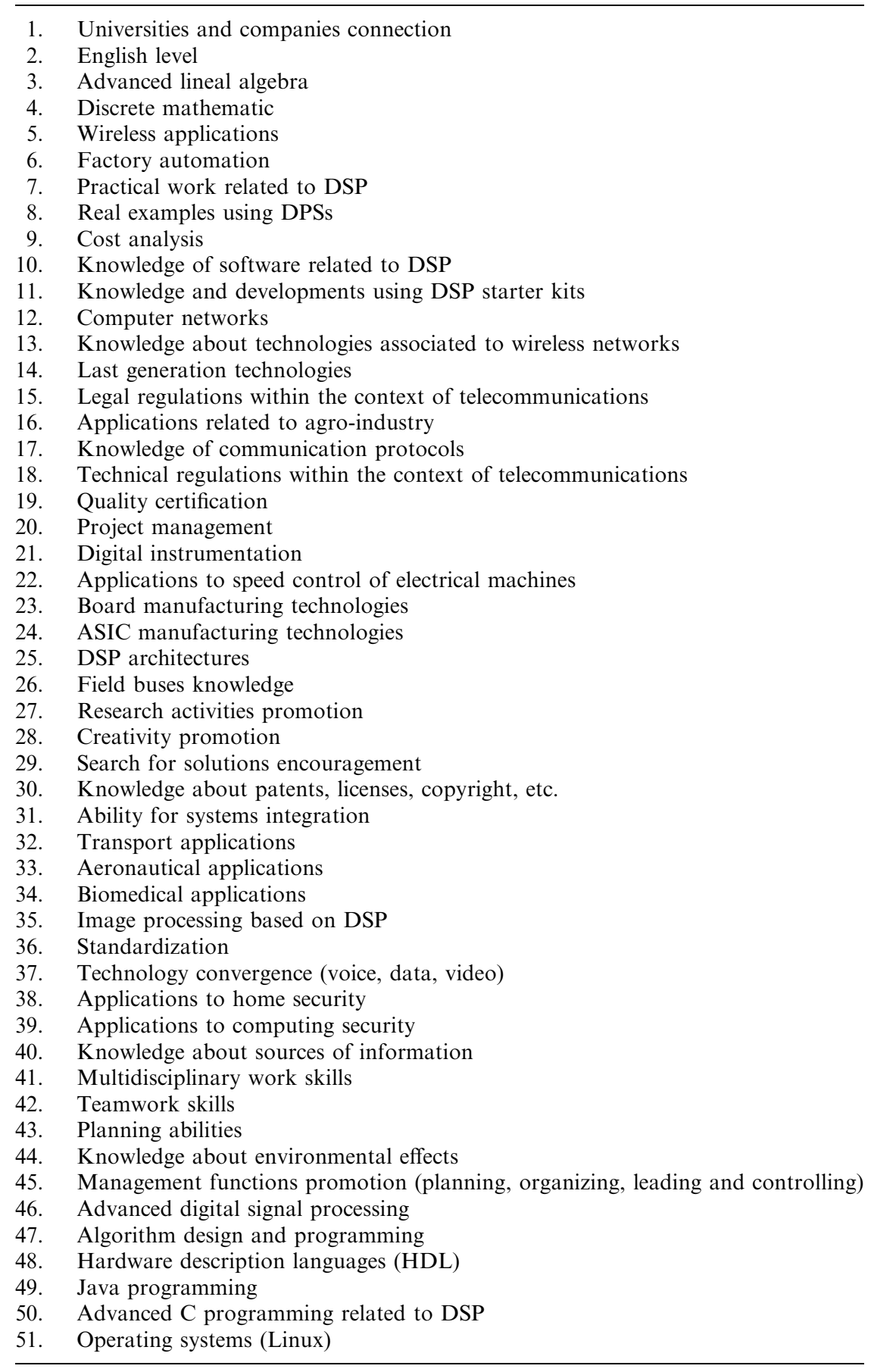


TABLE II. Continued

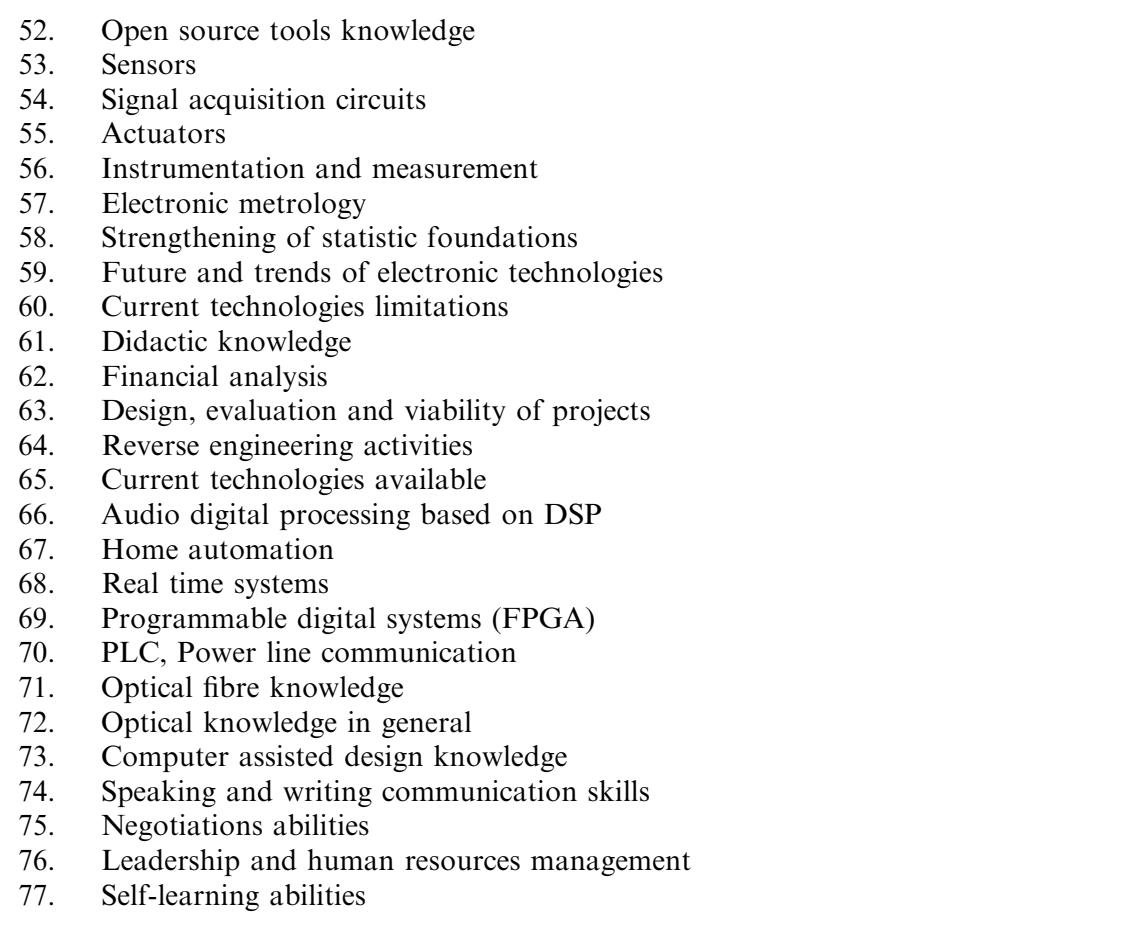

declarations made during the brainstorming session. It is based on the results of the similarity matrix of the classified task. The most common approach used to determine the coordinates of the objects is an iterative process, commonly referred to as the Shepard-Kruskal algorithm (Fahrmeir \& Hamerle 1984).

The multidimensional scale gives to the analyst a specific number of dimensions to represent the set of points. If a one-dimensional solution is required, all the points will form one line. A two-dimensional solution will place the set of points on a plane. The analyst should be able to use these dimensions. Interpretation of solutions with more than three dimensions is difficult. Therefore, when using concept maps twodimensional graphs are usually used.

In this case, the different items were distributed on a two-dimensional plane, starting from the similarity matrix, in such a way that the distance between the different items is inversely proportional to their affinity. That is, those items placed closer to each other are conceptually more closely related than those that are placed further in the plane. By representing the information in a two-dimensional space, the loss of information to obtain a less complicated interpretation of the information is acceptable. 
The cluster analysis organizes the information coming from the multidimensional scale, not from the Similarity Matrix (Everitt 1993). Ward's algorithm was used for the cluster analysis since it offers more sensitive solutions and it can be better interpreted than other estimations (Ward 1963).

Initially, the cluster analysis consider each item as its own cluster, thus obtaining a solution of $N$ clusters, in this case 77, corresponding to the number of identified items. For each level of analysis, Ward's algorithm combines two clusters until finally all the items are combined into just one cluster. Determination of the number of clusters to be used in the final solution is important. Therefore, care should be taken when examining the different types of possible cluster solutions to identify the ones that make sense. As a rule use of the number of clusters that errs by excess, rather than by defect is normal; in other words, a larger number of clusters are preferred to having a cluster containing heterogeneous concepts.

Once the multidimensional scale and the cluster analysis are carried out, a point map and a cluster map are formed. The final analysis requires an average score for each participant for each item and for each cluster, forming a point-rating map and a cluster-rating map.

\section{Interpretation of maps}

In order to interpret the maps, a final workgroup was organized. Generally, the results derived from the cluster analysis are more difficult to interpret than those from the multidimensional scale. The cluster analysis is seen as an indicator. At times, one would like to 'visually arrange' the clusters into sensitive parts so that the multidimensional space could be interpreted more easily. The key is to maintain the integrity of the multidimensional scale results by achieving a solution that will not allow the clusters to overlap. A consensus of the names given to the different clusters must be reached, using as a starting point those names given to the groups by the participants.

\section{CONCEPT-MAPPING APPLICATION RESULTS}

The rating point map of Figure 1 is the result of multidimensional scaling. Each number represents an item of Table II. The distance between points is a measure of affinity. Closer items are more closely related to each other while further points show a high level of dissimilarity.

The resultant map is a bidimensional approach of the distances obtained from the sum of each participant similarity matrix. In the upper left-hand corner of the figure, the correspondence between layers and numerical Likert values are shown.

Once the bidimensional representation of the 77 items is achieved, the items must be grouped in homogeneous clusters. These clusters will 


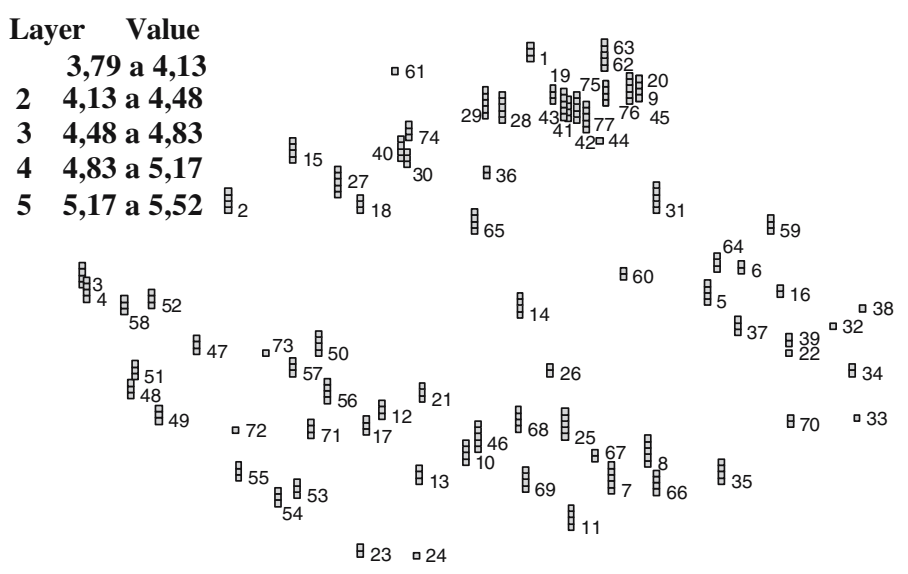

Figure 1. Rating point map obtained from multidimensional scaling.

define the resulting master's level curriculum. The result of the cluster analysis is summarized in Figure 2. According to Wards' algorithm, the items are grouped in 16 clusters. The concurring denominations of the sixteen clusters are shown in Table III.

Analyzing the map ensued from the Figure 2, there can be estimated three big regions highlighted in Figure 3 and Table II.

The first region, placed in the top part of Figure 3, refers to the management and legal regulation knowledge, as well as to the skills that the futures graduates should acquire. It will be named in a generic way 'ICT management' region, and agglutinates the clusters shown in Table IV.

The second region placed in the top part of Figure 3 refers to the knowledge of basic and applied sciences into which the program master

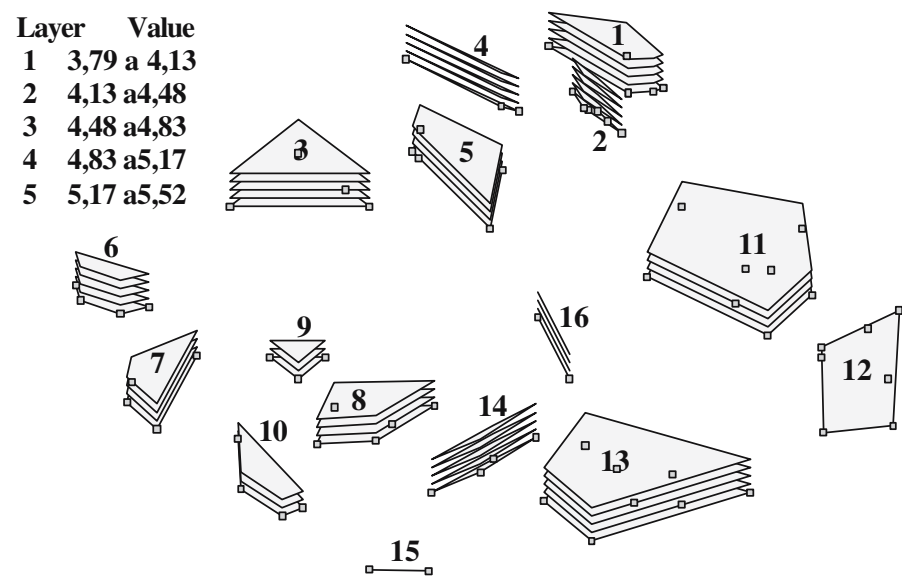

Figure 2. Cluster rating map. 


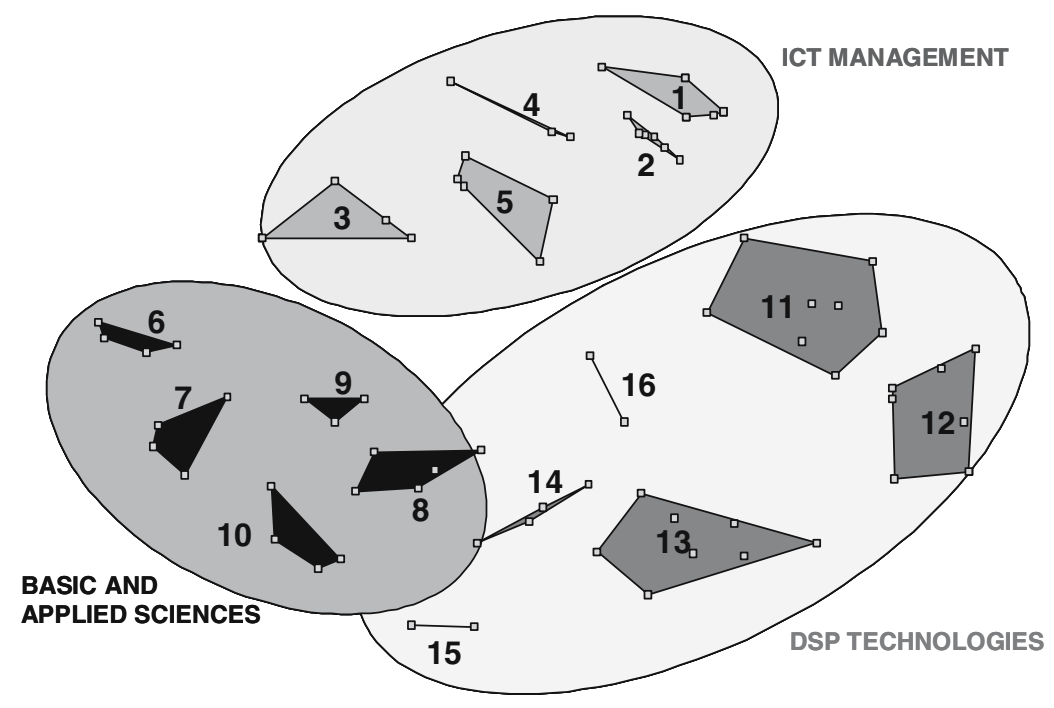

Figure 3. Detected regions in the cluster map.

must go deeply into, with regard to the current knowledge of the admitted graduate students. This region is called "basic and applied sciences deepening', and it is formed also by the clusters shown in Table V.

The third party region placed in the low right part of Figure 3 refers to digital signal processing and digital signal processors. It is generically named 'DSP technology' and is formed by six clusters, Table VI.

Finally, from the cluster rating map of Figure 2 there can be obtained the relative weight of the different matters that shape the program. In the low left corner of this figure, it can be observed the meaning of each layer. The lower values correspond to cluster 15, electronic circuit manufacturing technology, and cluster 12 , current and future applications of DSP. The rest of the clusters are highly valued respect the previous ones. The relative weight of each cluster can be used as a measure of the number of hours of that matter in the final master programme.

\section{Reliability analysis}

To measure their reliability the data matrix structure is inverted (with respect to traditional theory), so the persons are placed in columns and the items (or pairs of items) are placed in rows. The value of reliability is focused on consistency via the group of supposedly homogeneous participants. In that respect, it is helpful to talk about the reliability of the similarity matrix or the reliability of the map, but not of the reliability of individual statements (Trochim 1993). 
TABLE III

Cluster analysis results

\begin{tabular}{ll}
\hline Cluster & Denomination \\
\hline 1 & Business administration \\
2 & Management skills \\
3 & Legal topics \\
4 & Conceptual skills \\
5 & Standards and documentary sources \\
6 & Mathematics orientated to DSP \\
7 & Advanced computing \\
8 & Communication networks \\
9 & Electronic instrumentation \\
10 & Sensors and actuators \\
11 & DSP applications \\
12 & Current and future applications of DSP \\
13 & DSP: architectures and programming \\
14 & Advanced digital signal processing \\
15 & Electronic circuits manufacturing technologies \\
16 & Current and future electronic technologies \\
\hline
\end{tabular}

The key product of the concept mapping process is the two-dimensional map itself, and, consequently, the efforts made to verify the reliability are directed toward the central phases of analysis, development, and representation.

In a study published by Trochim (1993), the reliability of concept mapping was tested by six coefficients that could be easily estimated from the available data on any concept map project.

TABLE IV

ICT management clusters

Cluster 1: Business administration. It refers to managerial functions knowledge, projects and of human resources management, financial and cost analysis, and project viability evaluation

Cluster 2: Management skills. Engineers need certain skills to perform the duties and activities associated with being a manager

Cluster 3: Legal area. It refers to the knowledge of the technical and legal regulation in the area of the communications

Cluster 4: Conceptual skills. They refer to the skill of thinking and conceptualizing about abstract and complex situations. Using these skills, engineers must be able to see the organization as a whole, understand the relationships among various subunits, and visualize how the organization fits into its broader environment. Conceptual skills include the ability to use information to solve problems, the identification of opportunities for innovation, the recognition of problem areas and the implementation of solutions, the selection of the critical information from masses of data, the detection of improvement opportunities making an appropriate use of technologies, etc.

Cluster 5: Standards and documentary sources. They refer to the knowledge of the standards of normalization and of the documentary sources related to the area of the information and communication technologies 
TABLE V

Basic and applied sciences deepening

Cluster 6: Mathematics orientated to DSPs. It refers to the strengthening of discrete mathematics, z-transform, linear algebra and foundations of statistics, DFT, DTFT, wavelet

Cluster 7: Advanced computer science. Knowledge of programming algorithm, programming orientated to microprocessor devices, programming in Java and its application to mobile devices, multimedia and Flash. e-learning, real time operative systems, network security

Cluster 8: Communication networks. Local and wide area network, WI-FI technology, network access technologies (LMDS, PLC, RDSI, ADSL, CATV, TDT, etc.), standards and protocols

Cluster 9: Electronic instrumentation. It refers to the managing and design of electronic basic instrumentation (polymeters, oscilloscopes, wave generators, power supply); advanced electronic instrumentation (logic analyzers, net analyzers, spectrum analyzers, vector analyzers, impedance meters); noise and electromagnetic interferences; and anechoic chamber and semi-anechoic chamber

Cluster 10: Sensors and actuators. Types of sensors and actuators. Signal acquisition. Analogic wave transmission. Optocoupler and isolations. Interferences and noise. Analogic filtering techniques. Analog to digital and digital to analog conversion

All the reliability estimators referred to in the concept maps and used in Trochim's reliability study were calculated for our study and were compared to the results obtained in Trochim's research (see Table VII). A high level of reliability was found in our concept maps. That is, the results fall between the established maximum and minimum values; the indicators were found to be valid and within the standards shown by Trochim.

TABLE VI

DSP technology clusters

Cluster 11: Applications of DSPS. Applications orientated to the agro industry, communications, and automation and control of industrial processes. Control of electromechanical devices and electronic power systems. Quality of electrical network. Renewable energies

Cluster 12: Current and future applications of DSP. Applications in electronic, aeronautical and aerospace instrumentation, bioengineering, home automation, auto motion. Voice and video over IP

Cluster 13: DSP: architecture and programming. Advanced digital signal processors, TMS320C6000 family: internal architecture, programming and development systems (Toral et al. 2005)

Cluster 14: Advanced digital signal processing. Audio and video processing. Digital filtering. Image and pattern recognition. Real time expert systems

Cluster 15: Electronic circuits manufacturing technologies. Computer assisted design. Printed circuits manufacturing technologies. Surface mounts technology. ASIC, FPGA, CPLD and PLD circuits. Hardware description languages

Cluster 16: Current and future technologies. Field buses. RFID and PLC technologies. Wireless technologies. Second and third generation mobile technologies. Positioning systems. Digital TV 
TABLE VII

Descriptive statistics for reliability estimates for 38 concept mapping projects

\begin{tabular}{lcccccc}
\hline & $R_{\mathrm{II}}$ & $r_{\mathrm{IT}}$ & $r_{\mathrm{IM}}$ & $r_{\mathrm{RR}}$ & $r_{\mathrm{SHT}}$ & $r_{\mathrm{SHM}}$ \\
\hline Number of projects & 33 & 33 & 33 & 37 & 33 & 33 \\
Mean & 0.815 & 0.929 & 0.863 & 0.783 & 0.833 & 0.551 \\
Median & 0.820 & 0.930 & 0.862 & 0.821 & 0.848 & 0.558 \\
Minimum & 0.670 & 0.882 & 0.740 & 0.427 & 0.724 & 0.259 \\
Maximum & 0.934 & 0.973 & 0.954 & 0.935 & 0.932 & 0.907 \\
SD & 0.070 & 0.022 & 0.047 & 0.121 & 0.054 & 0.155 \\
Our map & 0.804 & 0.940 & 0.909 & 0.803 & 0.917 & 0.875 \\
\hline
\end{tabular}

\section{CONCLUSION}

This paper refers to the development of a scientific method to define a master's level curriculum in the ICT area, and it has been obtained as the result of the international cooperation between the University of Seville (Spain) and the Catholic University of Asunción (Paraguay) funded by the International Cooperation Spanish Agency (AECI). The concept map methodology has been used to develop the curriculum adapting its content to the needs and requirements of the Paraguayan environment. This methodology guarantees that different points of view are reflected in the final result. A curriculum arisen only from an academic area would have a bias mainly academic that would cause a detachment with the needs of the job market. In the same way, the absence of the academic area would cause that the capacity of update and adjustment would be lost in a very changeable sector. This one is the reason for which in the development of the maps there have taken part people belonging to different areas (academic, labour, institutional, etc.), which enrich the final result. Likewise, all these people know the reality of the environment, and, in consequence, they are capable of proportionate tangible solutions to concrete situations.

With all this in mind, a multidisciplinary master program has been obtained. The final result brings three unlike areas of knowledge near as the engineering, the computer science and the social sciences areas. This result will allow a better technological development of the sector, since it will be able to rely on professionals formed in the area of the ICT for which today there is not any specialized offer from the university world.

\section{ABOUT THE AUTHORS}

Sergio L. Toral Marín was born in Rabat, Morocco, in 1972. He received his Electrical Engineering and Ph.D. degrees at the University of Seville, Spain, in 1995 and 1999, respectively. He is currently a full Professor in the Electronic Engineering Department, Escuela Superior de Ingenieros 
of Seville. His research interests include microprocessor and DSP systems and their industrial applications, information and communication technologies and e-learning tools.

Rocío Martínez Torres was born in Madrid, Spain, in 1973. She received a degree in Business Administration in 1996, and her Ph.D. from the University of Seville, Spain, in 2003. She is currently a full Professor in the Business Administration and Marketing Department. Her research interests include intellectual capital and knowledge management.

Federico J. Barrero García was born in Seville, Spain, in 1967. He received his Electrical Engineering and Ph.D. degrees at the University Seville, Spain, in 1992 and 1998, respectively. In 1992, he joined the Department of Electronic Engineering at the University of Seville where he currently maintains a full Professor position. His current interests include microprocessor and DSP devices systems, Fuzzy Logic based system, control of electrical drives and power electronics, and information and communication technologies and e-learning tools.

Sergio Gallardo Vázquez was born in Huelva, Spain, in 1978. He received his Telecommunication Engineering degree in 2002, from the University of Seville, Spain. He is currently pursuing a Ph.D. degree at the School of Telecommunication Engineering, University of Seville, Spain. His research interests include DSP devices system, information and communication technologies and e-learning tools, and power electronics.

Enrique Vargas was born in Concepción, Paraguay in 1966. He received the degree in Electronic Engineering from the Faculdade de Engenharia Industrial (Sao Paulo, Brazil) in 1991. He received the Ph.D. degree from the Universidad Complutense de Madrid, in 1999. From 1999, Dr. Vargas is working at the Laboratorio de Electrónica Digital of Universidad Católica 'Nuestra Señora de la Asunción' in Asunción. His current areas of research include industrial automation and signal processing techniques specifically on ultrasound and optic signals.

Vicente González Ayala was born in Asunción, Paraguay in $1965 . \mathrm{He}$ received the Civil Engineering degree from the Universidad Católica 'Nuestra Señora de la Asunción' in Asunción in 1993. He received a M.Sc. degree in Industrial Automation from the Polytechnic University of Madrid, Spain. Since 1997, he is director of the Laboratorio de Electrónica Digital (LED) of the Universidad Católica 'Nuestra Señora de la Asunción' in Asunción. His current areas of research include industrial automation, computer architecture and digital signal processing. 


\section{REFERENCES}

Career-Space Project: 2001a, Generic ICT Skills Profiles, Office for Official Publications of the European Communities.

Career-Space Project: 2001b, Curriculum Development Guidelines New ICT curricula for the 21st Century: Designing Tomorrow's Education, Office for Official Publications of the European Communities.

Communiqué of the Conference of Ministers Responsible for Higher Education: 2003, Realising the European Higher Education Area, Berlín.

Delbecq, A. L., Van de Ven, A. H. \& Gustafson, D. H.: 1975, Group Techniques for Program Planning: A Guide to Nominal Group and DELPHI Processes, Scott Foresman and Company, Glenville, IL.

Everitt, B. S.: 1993, Cluster Analysis, Halsted Press.

Fahrmeir, L. \& Hamerle, A.: 1984, Multivariate Statistische Verfahren, De Gruyter, Berlin.

Joint Declaration on Harmonisation of the European Higher Education Area: 25th May, 1998, By the four Ministers in charge for France, Germany, Italy and the United Kingdom, Paris, the Sorbonne.

Joint Declaration of the European Ministers of Education: June 19th, 1999, 'The European Higher Education Area', Bologna.

Kolb, D. G. \& Shepherd, D. M.: 1997, 'Concept Mapping Organizational Cultures', Journal of Management Inquiry 6(4), 282-295.

Martínez-Torres, M. R., Barrero, F., Toral, S. L., \& Gallardo, S.: 2005, 'A Digital Signal Processing Teaching Methodology Using Concept Mapping Techniques', IEEE Transactions on Education $\mathbf{4 8}(3)$.

McCormick, R.: 2001, 'International Trends in Curriculum and Assessment', International Journal of Technology and Design Education 8(3), 307-312.

Thomson, C. J.: 1997, 'Concept Mapping as a Means of Evaluating Primary School Technology Programmes', International Journal of Technology and Design Education 7, 97-110.

Toral, S.L., Barrero, F., Martínez-Torres, M. R., Gallardo, S., \& Lillo, J.: 2005, 'Implementation of a Web-Based Educational Tool for Digital Signal Processing Teaching Using the Technological Acceptance Model', IEEE Transactions on Education, accepted for publication.

Trochim, W. M. K.: 1989, 'An Introduction to Concept Mapping for Planning and Evaluation', Evaluation and Program Planning 12(1), 1-16.

Trochim, W. M. K.: 1993, The Reliability of Concept Mapping, Annual Conference of the American Evaluation Association, Dallas, TX.

Trochim, W. M. K.: 1996, 'Criteria for Evaluating Graduate Programs in Evaluation', Evaluation News and Comment: The Magazine of the Australasian Evaluation Society 5(2), 54-57.

Vega Riveros, J. F., Marciales, G. P. \& Martínez, M.: 1998, 'Concept Maps in Engineering Education: A Case Study', Global Journal of Engineering Education 2(1), 21-27.

Ward, J. H.: 1963, 'Hierarchical Grouping to Optimize an Objective Function', Journal of the American Statistical Association 58, 236-244. 